\title{
Pharyngeal stricture treated by endoscopic adhesiolysis
}

Most pharyngeal strictures are treated with dilation, laser ablation or surgery. However, these methods may sometimes be ineffective, expensive or are associated with many complications. Therefore, we need to find a minimally invasive treatment alternative. To our knowledge, the efficacy of steroid injection combined with endoscopic balloon dilation has been verified in various studies [1]. And endoscopic radial incision and cutting has been used to treat patients with esophageal anastomotic strictures [2,3]. It is unclear whether endoscopic treatment is effective and safe for pharyngeal stricture.

A 34-year-old woman inhaled flames at the age of 2 years. She had experienced choking and aspiration of food and liquids. Endoscopy was performed when she was aged 34 years, revealing a severe pharyngeal stricture with severe scar adhesion and a partial defect of the epiglottis. The pediatric gastroscope was not able to pass through the hypopharyngeal area. The esophagogram revealed that the stricture was mainly in the hypopharynx, and the length was approximately 3-4 mm (• Fig. 1).

After a general discussion, we planned to perform the endoscopic cicatricotomy with electrosurgical knives (\$Video 1 ). First, we inserted a guidewire through the stricture. Next, an endoscope with a transparent cap attached to its tip was engaged to recognize the wall plane of hypopharynx to be incised. We incised the adhesion and scars with an insulation-tipped knife and hook knife until the endoscope was able to pass into the upper esophageal lumen ( $\mathbf{F i g . 2}$ ). Finally, we injected a long-acting steroid $(10 \mathrm{~mL}$, $50 \mathrm{mg}$ ) into the submucosa. There were no immediate or delayed complications. Endoscopic examination 6 months after dissection showed that the diameter of the stricture was $8 \mathrm{~mm}$. Therefore, we performed a second procedure of endoscopic adhesiolysis and cicatricotomy
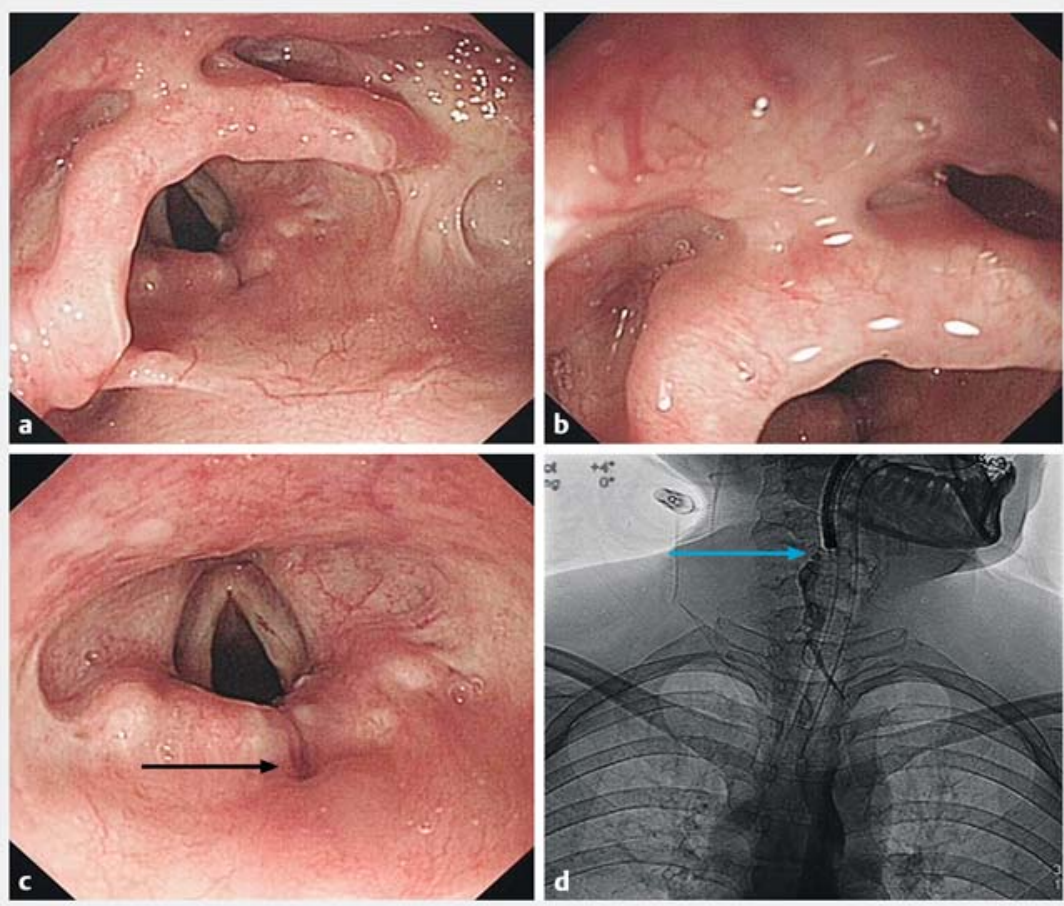

- Fig. 1 Examination with a pediatric gastroscope. a Endoscopy showed severe scar adhesion. $\mathbf{b}$ Endoscopy showed partial defect of the epiglottis and severe adhesive bands. c The diameter of the stricture was 1-2 mm (black arrow). $\mathbf{d}$ Esophagogram showing the stricture primarily in the hypopharynx and approximately $3-4 \mathrm{~mm}$ in length (blue arrow).
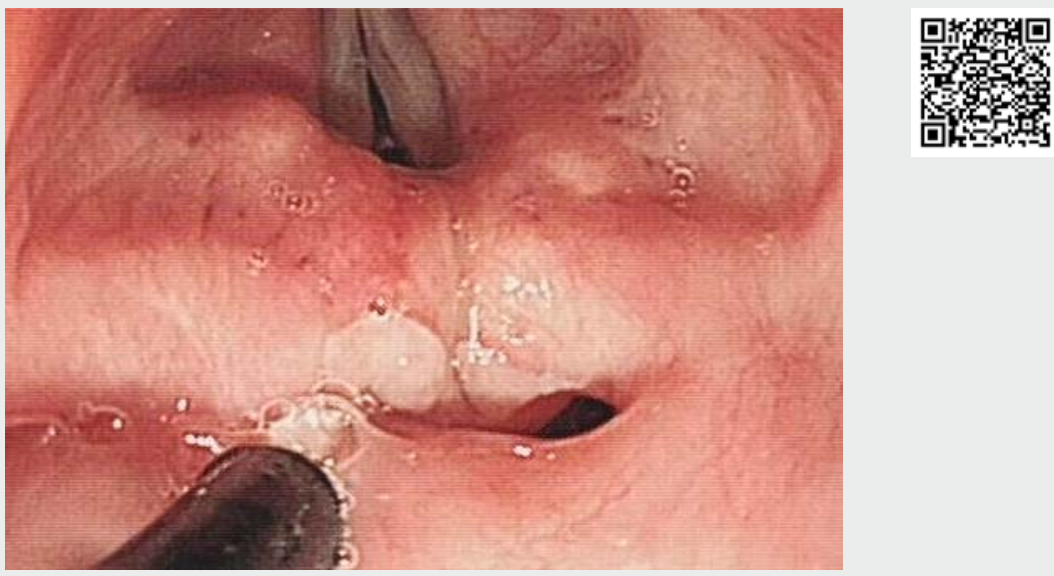

$\checkmark$ Video 1 Endoscopic treatment of pharyngeal stricture. Scar incision with insulationtipped knife and hook knife, and submucosal injection of long-acting steroid. 

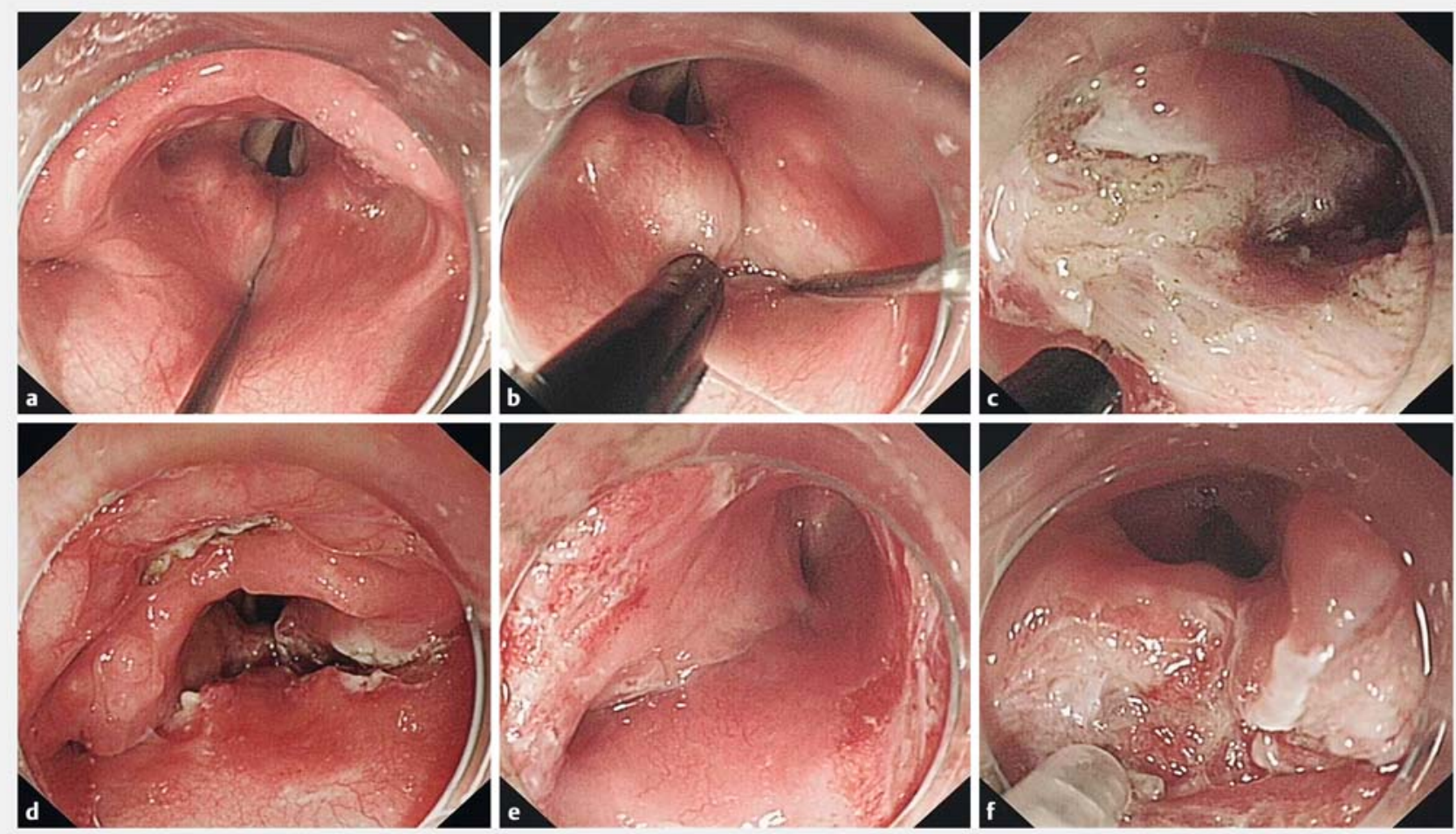

- Fig. 2 Dissection therapy. a The guidewire was inserted into the stricture under direct endoscopic view. b The insulation-tipped (IT) knife was inserted into the stricture under direct endoscopic view. c The mucosal adhesion and adhesive bands of the hypopharynx were dissected using an IT knife and a hook knife with transparent cap-fitted endoscope. $\mathbf{d}$ The dissection wound. $\mathbf{e}$ The endoscope was able to pass into the upper esophageal lumen after endoscopic adhesiolysis and cicatricotomy. $\mathbf{f}$ Long-acting steroid $(10 \mathrm{~mL}, 50 \mathrm{mg})$ was injected after dissection.

and submucosal injection of long-acting steroid. The patient has been visiting the outpatient department for 4 years, and endoscopy has shown no stricture recurrence.

Endoscopy_UCTN_Code_CCL_1AB_2AB

Acknowledgment

This work was supported by Chongqing Municipal Science and Technology Innovation Project for People's Livelihood (No. cstc2016shmszx130011).

\section{Competing interests}

None
The authors

Xia Xie, Jian-Ying Bai, En Liu, Xue Peng, FengYu Xiao, Shi-Ming Yang, Chao-Qiang Fan Department of Gastroenterology, Xinqiao Hospital, Army Military Medical University, Chongqing, China

Corresponding author

\section{Chao-Qiang Fan, MM}

Department of Gastroenterology, Xinqiao Hospital, Army Military Medical University, Chongqing 400037, China

Fax: +86-023-68774004

fcqxhkwjs@126.com
References

[1] Hashimoto S, Kobayashi M, Takeuchi M et al. The efficacy of endoscopic triamcinolone injection for the prevention of esophageal stricture after endoscopic submucosal dissection. Gastrointest Endosc 2011; 74: 1389-1393

[2] Muto M, Ezoe Y, Yano T et al. Usefulness of endoscopic radial incision and cutting method for refractory esophagogastric anastomotic stricture (with video). Gastrointest Endosc 2012; 75: 965 - 972

[3] Yano T, Yoda Y, Satake $\mathrm{H}$ et al. Radial incision and cutting method for refractory stricture after nonsurgical treatment of esophageal cancer. Endoscopy 2013; 45: 316-319

\section{Bibliography}

DOI https://doi.org/10.1055/a-0989-2345

Published online: 17.9.2019

Endoscopy 2020; 52: E78-E79

(c) Georg Thieme Verlag KG

Stuttgart · New York

ISSN 0013-726X 